\title{
Do | need a mentor or a coach?
}

Ann Rolfe

Mentoring Works, Umina Beach, Australia

Most people accept that ongoing personal and professional development is essential for success in any kind of work role. In many cases, mentoring or coaching is suggested as a way to obtain valuable personalised learning and growth. This article discusses how to determine if you need a coach or mentor, the distinctions between mentoring and coaching and contracting with a mentor or coach.

\section{The advantages of mentoring and coaching}

Many successful people identify mentors who assisted their development. Usually, these relationships were informal. They featured unstructured conversations, role modelling and supportive encouragement. Today, mentoring to support career progress and coaching in the workplace are more common than ever before.

This is because mentoring and coaching both:

(1) Provide one-to-one interaction to achieve personalised learning and growth;

(2) Cater to individual needs, personal styles and time constraints;

(3) Can be conducted face to face or from remote locations;

(4) Complement formal training and educational experiences;

(5) Process real-life issues, problems and decisions;

(6) Facilitate access to information and choices about new behaviors and actions;

(7) Support the achievement of positive outcomes.
While the need for ongoing development and the advantages of mentoring and coaching are clear, they are not a substitute for training and education. Nor do mentoring or coaching take over the line manager's responsibility for performance management. Rather, a mentor or coach fulfils individual development needs.

\section{Individual development needs}

A development need may be defined as a gap between where you are and where you want to be, that may be closed by acquiring knowledge and skills that increase ability.

The motivation for development may be:

(1) Self-satisfaction: your personal desire for learning and growth.

(2) Job requirements: changes in functions, procedures, technology, etc.

(3) Performance improvement: when self-assessment, or appraisal by others, indicates a need for adjustment.

(4) Career enhancement: increasing your opportunities for career satisfaction.

Mentoring and coaching complement development

Korean J Med Educ 2016 Dec; 28(4): 397-399.

https://doi.org/10.3946/kjme.2016.45

eISSN: 2005-7288

(C) The Korean Society of Medical Education. All rights reserved.

This is an open-access article distributed under the terms of the Creative

Commons Attribution Non-Commercial License (http://creativecommons.org/

licenses/by-nc/3.0/), which permits unrestricted non-commercial use, distribution,

and reproduction in any medium, provided the original work is properly cited. 
strategies such as:

(1) On-line or packaged training materials;

(2) Training courses;

(3) Formal education;

(4) On-the-job training; and

(5) Self-directed learning.

\section{Mentoring and coaching: recognizing the difference}

Although most people agree there are differences between the two, different people have very different ideas about what mentoring and coaching are. What one calls mentoring, another may call coaching. Regardless of what you call it, unrealistic expectations can undermine its effectiveness.

There are many types of mentoring and coaching. The focus here is on workplace mentoring which is most often associated with career development; in contrast to performance coaching, the sort of intervention that that focuses on a person's ability to do their job. I use the following distinctions:

(1) Coach: a person who trains, tutors or prepares an individual for improved skill and performance

(2) Mentor: one who guides and stimulates an individual's reflection and actions for improved personal and professional outcomes.

Table 1 shows the distinction between these types of mentoring and coaching [1].
Mentors and coaches use very similar skills. Rapport, trust and respect are needed for a satisfying relationship. Communication, observation, and feedback are features of both. Guidance and advice may be offered and practical rather than theoretical solutions to challenges are sought.

The roles of mentor, coach and even instructor, may merge sometimes. Within a mentoring relationship, coaching and instruction may occur at the invitation of the person being mentored. Coaches and instructors often act as mentors as they work with clients. What is important in working with a mentor or coach is negotiating the scope and style of the relationship from the outset.

\section{When to choose a mentor/when to choose a coach}

If you are clear that your development need requires the personalized approach, you must decide whether coaching or mentoring is more appropriate for you.

(1) Get a coach: when you have a well-defined goal that is based on improving specific skills and performance in your current role.

(2) Find a mentor: when you want to discuss broad career issues, seek general guidance, or need to clarify development goals, plan your future direction, make decisions or solve problems for yourself.

Table 1. Distinctions Performance Coaching/Mentoring for Development

\begin{tabular}{ll}
\hline \multicolumn{1}{c}{ Performance coaching } & \multicolumn{1}{c}{ Mentoring for development } \\
\hline Supports achievement of specific goals & Enables self-development of broad capabilities \\
Action oriented & Reflection emphasis \\
Concentrates on small steps & Concerned with the big picture \\
Attends to gap between actual and desired performance & Facilitates personal goal setting, action planning and implementation \\
Features practice of required performance, feedback and & Based on conversation, problem-solving, decision-making, creative and \\
correction & critical thinking processes \\
Results can be measured objectively & Results may be subjective and difficult to measure \\
Behavioural outcomes evident within a prescribed time-frame & Insight, personal and professional growth evolves over an indefinite time \\
\hline
\end{tabular}


A direct supervisor may coach you because they have a responsibility for performance management. However, mentoring is usually "off-line." In other words, the mentor is not someone above you in a direct line of authority. A mentor could be a peer, or someone more or less senior, within or outside of your workplace. For more about what to look for and where to find a mentor, see Article 4: "What to look for in a mentor."

\section{Contracting with your mentor or coach}

Unless you use a qualified psychologist, there is little regulation or quality control over any counsel you receive. Some coaches have been through an accreditation process and mentoring programs usually provide some training but there are few standard criteria of competencies for coaches or mentors. So you need to manage the relationship to ensure you get what you want.

A paying client negotiates a contract to get their expectations met. In voluntary mentoring or coaching you should also discuss, and agree from the beginning, what is and is not part of the arrangement. If your organization promotes mentoring or coaching, or there is a formal program, there will be guidelines that include definition of the roles and responsibilities of each party. There may be resources, including a written agreement provided. Human resources staff may help. Regardless of the support available, you need to take responsibility for reaching agreement with your mentor or coach about:

(1) The scope of the development you have in mind;

(2) The style of relationship you want;

(3) Confidentiality; and

(4) The amount of time and scheduling that works for both of you.

Obviously, if the coach or mentor is giving their time freely you need to be very respectful of this. Mentors and coaches have expectations too and it is wise to make these explicit. Handled as a friendly negotiation between professional colleagues, this first conversation is an opportunity to set the tone of future dialogue.

Although volunteer mentors and coaches enter the relationship with mainly altruistic motivation, they should obtain value from the experience. The process may enhance skills that can be transferred in other parts of their lives and work and the content of your conversations may provide insight to them as well as you. However, be sure to provide feedback about practical outcomes and benefits and show appreciation for their efforts.

\section{Reference}

1. Rolfe A. Mentoring: mindset, skills and tools. Kincumber South, Australia: Mentoring Works; 2012. 